\title{
Determination of Polar Compounds in Guava Leaves Infusions and Ultrasound Aqueous Extract by HPLC-ESI-MS
}

\author{
Elixabet Díaz-de-Cerio, ${ }^{1,2}$ Vito Verardo, ${ }^{3,4}$ Ana María Gómez-Caravaca, ${ }^{1,2}$ \\ Alberto Fernández-Gutiérrez, ${ }^{1,2}$ and Antonio Segura-Carretero ${ }^{1,2}$ \\ ${ }^{1}$ Department of Analytical Chemistry, Faculty of Sciences, University of Granada, Avenida Fuentenueva s/n, 18071 Granada, Spain \\ ${ }^{2}$ Functional Food Research and Development Center, Health Science Technological Park, Avenida del Conocimiento, \\ Bioregion Building, 18100 Granada, Spain \\ ${ }^{3}$ Department of Chemistry and Physics (Analytical Chemistry Area), University of Almería, Carretera de Sacramento $s / n$, \\ 04120 Almería, Spain \\ ${ }^{4}$ Research Centre for Agricultural and Food Biotechnology (BITAL), Agrifood Campus of International Excellence, ceiA3, \\ Carretera de Sacramento s/n, 04120 Almería, Spain
}

Correspondence should be addressed to Vito Verardo; vito.verardo@unibo.it

Received 10 December 2014; Revised 4 March 2015; Accepted 7 March 2015

Academic Editor: Serkos A. Haroutounian

Copyright (C) 2015 Elixabet Díaz-de-Cerio et al. This is an open access article distributed under the Creative Commons Attribution License, which permits unrestricted use, distribution, and reproduction in any medium, provided the original work is properly cited.

Literature lacks publications about polar compounds content in infusion or guava leaves tea. Because of that, a comparison between different times of infusion and a conventional ultrasound aqueous extract was carried out. Several polar compounds have been identified by HPLC-ESI-MS and their antioxidant activity was evaluated by FRAP and ABTS assays. Four different classes of phenolic compounds (gallic and ellagic acid derivatives, flavonols, flavanones, and flavan-3-ols) and some benzophenones were determined. The quantification results reported that the order, in terms of concentration of the classes of polar compounds in all samples, was flavonols $>$ flavan-3-ols $>$ gallic and ellagic acid derivatives $>$ benzophenones $>$ flavanones. As expected, the aqueous extract obtained by sonication showed the highest content in the compounds studied. Significative differences were noticed about the different times of infusion and five minutes was the optimal time to obtain the highest content in polar compounds using this culinary method. All the identified compounds, except HHDP isomers and naringenin, were positively correlated with antioxidant activity.

\section{Introduction}

The studies on antioxidant activity of plants have increased dramatically in recent years, because they are identified as natural antioxidant resources by traditional Chinese medicine [1]. Medicinal plants have usually been applied to control the blood glucose or reduce the diabetic complications; they have the potential to increase the life span and quality of life in these patients [2]. The increasing prevalence of type 2 diabetes mellitus and the negative clinical outcomes observed with the commercially available antidiabetic drugs have led to the investigation of new therapeutic approaches focused on controlling postprandial glucose levels. The use of carbohydrate digestive enzyme inhibitors from natural resources could be a possible strategy to block dietary carbohydrate absorption with less adverse effects than synthetic drugs. In fact, some authors [3] reported in vitro and in vivo studies in relation to pancreatic alpha-amylase inhibitors of plant origin and presented bioactive compounds of phenolic nature that exhibit anti-amylase activity.

Guava leaves (Psidium guajava L.) are considered native to Mexico but today they are extended throughout South America, Europe, Africa, and Asia. Different studies considered these leaves as a promising source of phenolic compounds for diabetes treatment [4]. Several authors noticed that oral administration of capsules containing aqueous leaf extract from Psidium guajava L. showed hypoglycemic effect [5]. 
Recently, Eidenberger and coworkers [6] investigated the effect of extracts from Psidium guajava L. leaves, particularly, the effects of main flavonol-glycoside components on dipeptidyl-peptidase IV (DP-IV), a key enzyme of blood glucose homoeostasis, and, finally, indicated that guava extract has a potential to exert the effect observed in vitro also in humans after oral administration.

In vivo experiments carried out by Cheng et al. [7] reported that quercetin in the aqueous extract of guava leaves promotes glucose uptake in liver cells and as a consequence contributes to the alleviation of hypoglycemia in diabetes.

Usually, guava leaf tea was consumed after infusion; however, different infusion times were advice from production company. Because of that, in the present work, the antioxidant activities of infusions obtained at different infusion times and conventional ultrasound aqueous extracts of guava leaves were evaluated and compared in terms of their composition in polar compounds.

\section{Material and Methods}

2.1. Chemicals. Double-deionised water with conductivity lower than $18.2 \mathrm{M} \Omega$ was obtained with a Milli-Q system (Millipore, Bedford, MA, USA). Methanol LC-MS "optima” grade and acetonitrile were obtained from Fisher Scientific (Leicestershire, UK). Acetic acid and the standards gallic acid, catechin, ellagic acid, naringenin, quercetin, and rutin were all from Sigma-Aldrich (Steinheim, Germany). The reagents used to measure the antioxidant capacity, TPTZ (2,4,6-tripyridyl-S-triazine), Trolox (6-hydroxy2,5,7,8-tetramethylchroman-2-carboxylic acid), ABTS $\left(2,2^{\prime}\right.$ azinobis (3-ethylbenzothiazoline-6-sulfonate)), potassium persulfate, and ferric sulfate, were purchased from SigmaAldrich (St. Louis, MO, USA). Sodium acetate, ferric chloride, and hydrochloric acid were obtained from Panreac (Barcelona, Spain).

2.2. Plant Material and Sample Preparation. Fresh guava leaves were harvested in Motril, Spain $\left(36^{\circ} 44^{\prime} 43^{\prime \prime} \mathrm{N}\right.$, $\left.3^{\circ} 31^{\prime} 14^{\prime \prime} \mathrm{O}\right)$. They were middle age intense green leaves and they were collected in February 2014. The environmental conditions had mean $\max / \mathrm{min}$ temperature of $18 / 10^{\circ} \mathrm{C}$, precipitation of $0 \mathrm{~mm}$, and saturated light duration that ranged from 9.55 to $10.50 \mathrm{~h} \mathrm{day}^{-1}$.

The samples were air-dried and ground before the analyses. Two different extraction methodologies, such as ultrasound extraction and infusion, were carried out.

Conventional Ultrasound Extraction. $0.5 \mathrm{~g}$ of dry guava leaves was extracted with $15 \mathrm{~mL}$ of water $(\times 3)$ using a sonicator Branson B3510 for $10 \mathrm{~min}$ at room temperature. Then, samples were centrifuged for $15 \mathrm{~min}$ at $6000 \mathrm{rpm}$ using a centrifuge to remove solids. The supernatants were pooled, evaporated, and dissolved in $2 \mathrm{~mL}$ of $50 \%$ methanol. This solution was filtered through a $0.20 \mu \mathrm{m}$ syringe filter and kept at $-20^{\circ} \mathrm{C}$ in amber bottles to avoid degradation until analysis.

Infusion Extraction. For the infusion, $1 \mathrm{~g}$ of dried guava leaves and $50 \mathrm{~mL}$ of boiling water were used. The extract was prepared according to the method previously described by Chen and Yen [8], where they prepared 5 min infusion and compared with infusion for 3 and $7 \mathrm{~min}$. After the extraction by infusion for 3,5 , and $7 \mathrm{~min}$, the solution was raised to $50 \mathrm{~mL}$ with water, filtered through a $0.20 \mu \mathrm{m}$ syringe filter, and kept at $-20^{\circ} \mathrm{C}$ in amber bottles to avoid degradation until analysis.

All extractions were made in triplicate.

2.3. Trolox Equivalent Antioxidant Capacity (ABTS) Assay. The ABTS assay, which measures the reduction of the radical cation of 2,2' -azinobis-(3-ethylbenzothiazoline-6-sulfonate) (ABTS) by antioxidants, was performed by using a method previously described by Laporta and coworkers [9]. Concisely, ABTS radical cation was produced by reacting ABTS stock solution with $2.45 \mathrm{mM}$ potassium persulfate in the dark at room temperature for $12-24 \mathrm{~h}$ before use. The absorbance of ABTS radical cation was adjusted to $0.70( \pm 0.02)$ at $734 \mathrm{~nm}$. A calibration curve was prepared with different concentrations of Trolox $(0-20 \mu \mathrm{M})$.

2.4. Ferric-Reducing Antioxidant Power (FRAP). The reducing power was evaluated according to the method validated by Benzie and Strain [10]. Briefly, $300 \mathrm{mM}$ acetate buffer (pH 3.6), $10 \mathrm{mM}$ TPTZ in $40 \mathrm{mM} \mathrm{HCl}$, and $20 \mathrm{mM}$ aqueous $\mathrm{FeCl}_{3}$ were prepared and mixed $(10: 1: 1)$, to obtain the FRAP reagent. The FRAP reagent was warmed to $37^{\circ} \mathrm{C}$, before reading its absorbance. Then, the samples were added. The change in absorbance $(593 \mathrm{~nm})$ between the samples and the blank was related to the absorbance of an aqueous solution of known Fe(II) concentration, prepared for calibration.

2.5. HPLC-ESI-MS Analysis. Phenolic and other polar compounds in the extracts obtained from guava leaves were identified using a method introduced by Chang et al. [11], with slight modifications. Briefly, HPLC analyses were performed using a HP 1100 Series instrument (Hewlett Packard, Wilmington, DE, USA) equipped with a binary pump delivery system, a degasser (model G1322A), an autosampler (Automatic Liquid Sampler, ALS, model G1312A), a HP diode-array UV-VIS detector (DAD, model G1315A), and a quadrupole HP-Mass Spectrometer Detector (MSD, model G1946A); integration and data elaboration were performed using Chemstation software (Hewlett Packard). A Phenomenex Luna C18 analytical column $(150 \mathrm{~mm} \times 2.0 \mathrm{~mm}$, particle size $3 \mu \mathrm{m}$ ) (Phenomenex Inc., Torrance, CA, USA) was used for polar compounds separation. All analyses were carried out at room temperature using the gradient proposed by Chang et al. [11]. MS analysis was carried out using an electrospray ionization (ESI) interface in negative ionization mode at the following conditions: drying gas flow $\left(\mathrm{N}_{2}\right), 9.0 \mathrm{~L} / \mathrm{min}$; nebulizer pressure, $50 \mathrm{psi}$; gas drying temperature, $350^{\circ} \mathrm{C}$; capillary voltage, $3500 \mathrm{~V}$; and fragmentor voltage and scan range, $100 \mathrm{~V}$ and $m / z 50-1000$, respectively.

Phenolic standards of interest such as gallic acid, catechin, ellagic acid, naringenin, and rutin were used for quantification of phenolic compounds in guava leaf extracts. The identified compounds were quantified on the basis of their peak area and compared with calibration curves obtained 
with the corresponding standards and then expressed as $\mu \mathrm{g} / \mathrm{g}$ of extract.

2.6. Statistical Analysis. The results reported in this study are the averages of three repetitions $(n=3)$. Fisher's least significance difference (LSD) test and Pearson's linear correlations, both at $P<0.05$, were evaluated using Statistica 6.0 (2001, StatSoft, Tulsa, OK).

\section{Results and Discussion}

3.1. Identification of Polar Compounds. Phenolic and other polar compounds were identified by their elution order, UV/vis spectra, and MS characteristics, compared with reported literature values, and by coinjection with available standards (Table 1).

About phenolic compounds, four different classes identified as gallic and ellagic acid derivatives, flavonols, flavanones, and flavan-3-ols were determined.

Thirteen gallic and ellagic acid derivatives were determined. Three compounds (1, 2, and $\mathbf{3})$ with molecular ion at $m / z 481$ and fragment at $m / z 301$ were identified as hexahydroxydiphenic acid (HHDP) glucose and its presence in guava was previously reported by Okuda and coworkers [12]. Gallic acid (compound 4) was identified according to its MS data $(\mathrm{m} / z 169$ and $\mathrm{m} / z$ 125) and by coelution with a chemical standard. Two compounds (6 and 11) with $[\mathrm{M}-\mathrm{H}]^{-}$at $\mathrm{m} / \mathrm{z}$ 783 and two fragments at $\mathrm{m} / z 481$ and 301 corresponding to loss of ellagic acid were detected. This fragmentation pattern was assigned to pedunculagin/casuariin compounds; these compounds were described in guava leaves by Okuda et al. [12].

Two compounds (10 and 12) with molecular ion at $\mathrm{m} / \mathrm{z}$ 951 and fragments at $m / z 783$ and 481 were also determined. These compounds were identified as geraniin isomers [13].

Two compounds (15 and 18) showing significant $[\mathrm{M}-\mathrm{H}]^{-}$ signals at $m / z 785$ with fragment ions at $m / z 615$ and at $m / z$ 301 were found. This fragmentation pattern corresponded to a digalloyl-HHDP-glucose structure, probably tellimagrandin I isomer. This compound was previously detected in guava leaves by Okuda et al. [12]. Compound 17 at $m / z 935$ reported a fragment ion at $m / z 783$; this fragmentation pattern was assigned to casuarinin/casuarictin and this compound was described in guava tea by Yamanaka and coworkers [13]. Compound 30 was identified as ellagic acid due its coelution with commercial standard. Finally, guavin B (compound 46) that reported a molecular ion at $\mathrm{m} / \mathrm{z} 693$ was identified according to Okuda et al. [14].

Moreover, ten flavan-3-ol derivatives were determined. Compounds $\mathbf{5}$ and $\mathbf{4 2}$ showed a molecular ion at $m / z 609$ and three fragments at $m / z 441,423$, and 305 (gallocatechin unit); these compounds were identified as prodelphinidin B2 and its isomer and their presence in guava leaves was noticed by Qa'Dan et al. [15].

Compounds 7 and 9 showed a molecular ion at $m / z 593$ and two fragments at $m / z 425$ and 407. According to Qa'Dan et al. [15], these compounds were identified as prodelphinidin dimer $(4 \alpha-8)$.
Two compounds (8 and 19) with $[\mathrm{M}-\mathrm{H}]^{-}$at $\mathrm{m} / \mathrm{z} 305$ and fragment ions at $\mathrm{m} / \mathrm{z} 221$ and 179 were identified as gallocatechin isomers and their presence in guava leaves was reported by Qa'Dan et al. [15]. Three procyanidin dimers $\left([\mathrm{M}-\mathrm{H}]^{-}\right.$at $m / z 577$ ) were also described (compounds $\mathbf{1 3 , 1 4}$, and 21).

Catechin compound (16) was identified by mass spectra data elaboration and coelution with a commercial standard.

The flavonols were the most representative phenolic compounds; in fact, eighteen flavonol-derivatives were identified. Four compounds (compounds 20, 24, 27, and 29) reported a molecular ion at $m / z 449$ and two major fragments at $m / z 316$ and 317. According to Chang et al. [11], these compounds were identified as myricetin-arabinoside/xylopyranoside isomers.

Two flavonol compounds (compounds 22 and 23) with molecular ion at $\mathrm{m} / \mathrm{z} 479$ and fragments at $\mathrm{m} / \mathrm{z} 317$ and 316 were identified as myricetin-hexoside isomers [11]. Two compounds (25 and 26) corresponding to $[\mathrm{M}-\mathrm{H}]^{-}$signals at $\mathrm{m} / z 615$ were also detected. Based on their molecular weight and the presence of two fragments at $m / z 463$ and 301, they were assigned to quercetin-galloylhexoside isomers and their presence in guava leaves was reported by Park et al. [16].

Two compounds at $\mathrm{m} / \mathrm{z} 301$ were detected (28 and 47); moreover, they showed the same fragment ion at $\mathrm{m} / z 151$. Quercetin standard solution was injected and because of that compound $\mathbf{2 8}$ was assigned to morin and compound $\mathbf{4 7}$ was assigned to quercetin; their presence in guava leaves was reported by several authors [11, 17].

Compounds detected at $\mathrm{m} / \mathrm{z} 463$ (31 and 33) with fragment ion at $\mathrm{m} / \mathrm{z} 301$ corresponded to hyperin and isoquercitrin, respectively. They have previously been found in leaves of guava by Eidenberger et al. [6].

Quercetin glucuronide (32) with molecular ion at $m / z 477$ and fragment ions at $m / z 433$ and 301 was identified according to Chang et al. [11].

Three compounds $(\mathbf{3 4}, \mathbf{3 5}$, and 37$)$ reported the same molecular ion $(\mathrm{m} / z$ 433) and a fragment ion at $\mathrm{m} / \mathrm{z} 301$ (corresponding to quercetin aglycone); according to their retention times, they were identified as reynoutrin, guajaverin, and avicularin as reported by Chang et al. [11].

Quercitrin (38) was identified at $\mathrm{m} / \mathrm{z} 447$ and fragment ion $m / z 300$, according to Park et al. [16].

A flavanone compound, namely, naringenin $(\mathrm{m} / z$ 271), was detected and identified by analyzing the mass spectra and by coelution with a chemical standard [18]. Compound $\mathbf{3 9}$ with $m / z 585$ was identified as guavinoside $C$ [19].

Six benzophenone compounds were also determined in guava leaves sample. The $[\mathrm{M}-\mathrm{H}]^{-}$ion at $m / z 543$ revealed the presence of two compounds, namely, guavinoside A isomers; their presence in guava leaves was noticed by Matsuzaki and coworkers [19].

Finally, four compounds with $m / z 571(\mathbf{4 0}, \mathbf{4 3}, \mathbf{4 4}$, and 45) were identified as guavinoside $B$ isomers according to Matsuzaki et al. [19].

3.2. Quantification of Polar Compounds. Comparison between different times of infusion and a conventional ultrasound aqueous extract was carried out due to several 
TABLE 1: Identification of polar compounds in guava leaves by HPLC-DAD-ESI-MS.

\begin{tabular}{|c|c|c|c|c|}
\hline Number & Compounds & $\lambda_{\max }(\mathrm{nm})$ & {$[\mathrm{M}-\mathrm{H}]^{-}$} & Fragments \\
\hline 1 & HHDP glucose isomer & 290 & 481 & 301 \\
\hline 2 & HHDP glucose isomer & 290 & 481 & 301 \\
\hline 3 & HHDP glucose isomer & 290 & 481 & 301 \\
\hline 4 & Gallic acid & 272,225 & 169 & 125 \\
\hline 5 & Prodelphinidin B2 isomer & 280,360 & 609 & $423,441,305$ \\
\hline 6 & Pedunculagin/casuariin isomer & 253,377 & 783 & 481,301 \\
\hline 7 & Prodelphinidin dimer isomer & 280,340 & 593 & 407,425 \\
\hline 8 & Gallocatechin & $236,270 \mathrm{sh}$ & 305 & 179,221 \\
\hline 9 & Prodelphinidin dimer isomer & 280,340 & 593 & 407,425 \\
\hline 10 & Geraniin isomer & 270 & 951 & $783,481,301$ \\
\hline 11 & Pedunculagin/casuariin isomer & 253,377 & 783 & 481,301 \\
\hline 12 & Geraniin isomer & 270 & 951 & 783,481 \\
\hline 13 & Procyanidin B isomer & 278,234 & 577 & 289 \\
\hline 14 & Procyanidin B isomer & 278,235 & 577 & 289 \\
\hline 15 & Tellimagrandin I isomer & 279,340 & 785 & 615,301 \\
\hline 16 & Catechin & 236,281 & 289 & $245,205,179$ \\
\hline 17 & Casuarinin/casuarictin isomer & $238,275 \mathrm{sh}$ & 935 & 783 \\
\hline 18 & Tellimagrandin I isomer & 277,338 & 785 & 615,301 \\
\hline 19 & Gallocatechin & 236,270 sh & 305 & 179,221 \\
\hline 20 & Myricetin-arabinoside/xylopyranoside isomer & $264,231 \mathrm{sh}, 356$ & 449 & 316,317 \\
\hline 21 & Procyanidin B isomer 2 & 268,350 & 577 & 425,289 \\
\hline 22 & Myricetin hexoside isomer & 261, 231sh, 358 & 479 & 316,317 \\
\hline 23 & Myricetin hexoside isomer & $264,235 \mathrm{sh}, 356$ & 479 & 316,317 \\
\hline 24 & Myricetin-arabinoside/xylopyranoside isomer & $264,231 \mathrm{sh}, 356$ & 449 & 316,317 \\
\hline 25 & Quercetin-galloylhexoside isomer & 268,350 & 615 & 463,301 \\
\hline 26 & Quercetin-galloylhexoside isomer & 280,345 & 615 & 463,301 \\
\hline 27 & Myricetin-arabinoside/xylopyranoside isomer & $256,234 \mathrm{sh}, 356$ & 449 & 316,317 \\
\hline 28 & Morin & 232sh, 257, 374 & 301 & 151 \\
\hline 29 & Myricetin-arabinoside/xylopyranoside isomer & 257, 231sh, 356 & 449 & 316,317 \\
\hline 30 & Ellagic acid & 254,370 & 301 & 257,185 \\
\hline 31 & Hyperin & $259,355,235 \mathrm{sh}$ & 463 & 301 \\
\hline 32 & Quercetin glucuronide & $265,355,233 \mathrm{sh}$ & 477 & 301,433 \\
\hline 33 & Isoquercitrin & $258,355,235 \mathrm{sh}$ & 463 & 301 \\
\hline 34 & Reynoutrin & $258,356,231 \mathrm{sh}$ & 433 & 301 \\
\hline 35 & Guajaverin & $257,356,231 \mathrm{sh}$ & 433 & 301 \\
\hline 36 & Guavinoside A & 218,288 & 543 & - \\
\hline 37 & Avicularin & $257,355,231$ sh & 433 & 301 \\
\hline 38 & Quercitrin & 264,353 & 447 & 300 \\
\hline 39 & Guavinoside C & $211,265,355$ & 585 & - \\
\hline 40 & Guavinoside B & 218,283 & 571 & - \\
\hline 41 & Guavinoside A isomer & 218,288 & 543 & - \\
\hline 42 & Prodelphinidin B2 isomer 2 & 282,340 & 609 & $423,441,305$ \\
\hline 43 & Guavinoside B isomer & 218,283 & 571 & - \\
\hline 44 & Guavinoside B isomer & 218,283 & 571 & - \\
\hline 45 & Guavinoside B isomer & 218,283 & 571 & - \\
\hline 46 & Guavin B & $208,221,283$ & 693 & - \\
\hline 47 & Quercetin & 232sh, 257, 374 & 301 & 151 \\
\hline 48 & Naringenin & 280 & 271 & - \\
\hline
\end{tabular}


publications about phenolic and other polar compounds content in infusion or guava leaves tea.

Quantification of polar compounds was performed by preparing five calibration curves with the standards available: gallic acid, catechin, ellagic acid, naringenin, and rutin. For those with no commercial standard available, quantification was carried out comparing with compounds bearing similar structures.

It is important to underline that the quantification results reported that the order, in terms of concentration of the families of polar compounds in all samples, decreased in the following order: flavonols $>$ flavan-3-ols $>$ gallic and ellagic derivatives $>$ benzophenones $>$ flavanones.

In general, the results given in Table 2 show that the concentration of each compound is greater in the ultrasound aqueous extract (AE), except the compounds identified as HHDP glucose that was higher in the infusion of $3 \mathrm{~min}$ (I3) and in the $5 \mathrm{~min}$ (I5) samples and naringenin, which presented the largest concentration in I3. Similar results were obtained by Nantitanon and coworkers [20] using ethanol as extraction solvent. In fact, they extracted the guava leaves by maceration and ultrasounds, and the highest recovery of phenolic compounds was obtained by sonication.

The higher extraction of HHDP and naringenin in some infusions than ultrasound extraction could be justified by the temperature that has been reached during the two extraction methodologies. As reported by Zhang and coworkers [21] the solubility of naringenin gradually increases as the temperature increases; based on these results, it is expected to obtain lower extraction of these compounds during ultrasound extraction instead of that of infusion. This hypothesis can be confirmed with the results obtained by Wen et al. [22] that noticed that naringenin is insoluble in water at room temperature.

However, naringenin content in infusion samples reported a decreasing trend when increasing the time of infusion; these results should be attributed to a degradation of this compound when the thermal treatment was prolonged.

To the best of our knowledge, there is no literature about the water solubility and the effect of temperature on HHDP compound. Nevertheless, taking into account the results reported in Table 2, a similar trend to the one reported for naringenin compound could be supposed for HHDP.

Flavan-3-ols, gallic and ellagic acid derivatives, benzophenones, and flavonols in the ultrasound aqueous extract were from 3 to 5 times more concentrated than leaves infusions. Compared to the ultrasound aqueous extract (AE) and infusion of $7 \mathrm{~min}$ (I7) samples, naringenin was 1.5 and 1.7 times higher in the infusion of $3 \mathrm{~min}$ (I3) and in the $5 \mathrm{~min}$ (I5) samples, respectively.

Flavonols represent about 50 percent of total polar compounds in each sample. Avicularin and guajaverin were the major flavonol components and their concentrations varied from 13.7 to $3.2 \mathrm{mg} / \mathrm{g}$ and from 12.8 to $2.7 \mathrm{mg} / \mathrm{g}$, respectively. Similar trend was showed by Chang et al. [11]. Morin was also found in high concentration with a range that varies from 3.0 to $8.4 \mathrm{mg} / \mathrm{g}$ in I7 and AE sample, respectively. Other flavonol compounds presented in all samples in higher quantities and in the same order of magnitude were hyperin, quercitrin, reynoutrin, and isoquercitrin. Myricetin-arabinoside was detected in all samples, but it was quantified only in $\mathrm{AE}$ sample; instead, quercetin was only detected and quantified in the AE sample. These data could promote the use of guava leaves extract for nutraceutical scopes because, as reported by Wang et al. [23], myricetin and quercetin have high inhibitory activities against some enzymes that are involved in diabetes. Guavinoside $C$ was quantified in ultrasound aqueous extract; it was identified in infusion samples, but its content was lower than LOQ.

The second class of polar compounds was represented by flavan-3-ols, which correspond to $26-30 \%$ of total polar compounds. Procyanidin was the first polar compound and its amounts ranged from 6.1 to $17.7 \mathrm{mg} / \mathrm{g}$. Catechin was the second flavan-3-ol ranging between 5.1 and $12.9 \mathrm{mg} / \mathrm{g}$.

Two epigallocatechin isomers and prodelphinidin dimer were the third flavan-3-ols and their amounts were about 5.4$5.9 \mathrm{mg} / \mathrm{g}$.

Gallic and ellagic acid derivatives account for $20 \%$ of the total concentration of polar compounds in each sample. In this case, ultrasound aqueous extract and infusions reported different extraction power. Effectively, ultrasound aqueous extract showed casuarinin/casuarictin as first ellagic acid derivative $(8.7 \mathrm{mg} / \mathrm{g})$; on the contrary, infusion samples reported HHDP glucose compounds in the highest amounts $(2.0-2.3 \mathrm{mg} / \mathrm{g})$. Benzophenones were $2-4 \%$ of total polar compounds. Guavinoside A was the first benzophenone and it was represented by two isomers. Finally, four guavinoside $B$ isomers were also detected in the extract, but only one was quantified; their content in infusion samples was less than LOQ or, in some cases, they were not detected.

At last, a flavanone, namely, naringenin was presented in all samples; I3 sample showed the higher content; on the contrary, aqueous extract and I7 samples reported the lowest quantities.

\subsection{Comparison between Phenolic Content and Antioxidant} Activity. As shown in Figure 1, the amount of total polar compounds is significantly higher in the ultrasound aqueous extract than in the infusions. Comparing the results obtained for the infusions, the quantity of these compounds is quite higher for I5 than for the others, I3 and I7. In fact, I3 sample reported a lower content probably due to an incomplete extraction of polar compounds; instead, I7 sample showed lower amounts, probably due to a degradation of these compounds during maceration.

To evaluate the antioxidant activity of the extract and to corroborate the correlation between phenolic content and antioxidant activity, two different assays were developed: TEAC evaluated by $\mathrm{ABTS}^{\bullet+}$ test and FRAP.

The choice of these two methods was assessed based on their different mechanisms: the radical scavenging capacity demonstrated by ABTS and ferric reducing capacities evaluable by FRAP method. Moreover, the results obtained by Thaipong et al. [24] demonstrated that ABTS and FRAP reported higher correlation with total phenolic content in guava fruit compared to other antioxidant activity assays.

Total polar compounds by HPLC are in concordance with the values obtained for the FRAP and ABTS assays 
TABLE 2: Quantification (mean $\pm \mathrm{SD}, n=3$ ) of the compounds identified in guava leaves infusions and ultrasound aqueous extract.

\begin{tabular}{|c|c|c|c|c|c|}
\hline \multirow{2}{*}{ Number } & \multirow{2}{*}{ Compounds } & \multicolumn{4}{|c|}{ Quantification ( $\mu$ g analyte/g leaves) } \\
\hline & & $\mathrm{AE}$ & I3 & I5 & I7 \\
\hline 1 & HHDP glucose isomer & $1146 \pm 34^{\mathrm{c}}$ & $2256 \pm 37^{\mathrm{a}}$ & $2253 \pm 27^{\mathrm{a}}$ & $2021 \pm 67^{b}$ \\
\hline 2 & HHDP glucose isomer & $228 \pm 40^{\mathrm{b}}$ & $441 \pm 72^{\mathrm{a}}$ & $368 \pm 59^{\mathrm{a}, \mathrm{b}}$ & $397 \pm 93^{\mathrm{a}, \mathrm{b}}$ \\
\hline 3 & HHDP glucose isomer & $1424 \pm 48^{\mathrm{c}}$ & $1756 \pm 39^{\mathrm{a}}$ & $1762 \pm 12^{\mathrm{a}}$ & $1546 \pm 27^{\mathrm{b}}$ \\
\hline 4 & Gallic acid & $719 \pm 33^{\mathrm{a}}$ & $240 \pm 5^{\mathrm{b}}$ & $260 \pm 5^{\mathrm{b}}$ & $254 \pm 9^{\mathrm{b}}$ \\
\hline 5 & Prodelphinidin B2 isomer & $665 \pm 55^{\mathrm{a}}$ & $212 \pm 11^{\mathrm{b}}$ & $220 \pm 12^{\mathrm{b}}$ & $126 \pm 8^{c}$ \\
\hline 6 & Pedunculagin/casuariin isomer & $2405 \pm 38^{\mathrm{a}}$ & $573 \pm 14^{\mathrm{c}}$ & $688 \pm 5^{\mathrm{b}}$ & $533 \pm 6^{\mathrm{c}}$ \\
\hline 7 & Prodelphinidin dimer isomer & $1768 \pm 90^{\mathrm{a}}$ & $444 \pm 26^{\mathrm{b}}$ & $467 \pm 20^{\mathrm{b}}$ & $335 \pm 11^{\mathrm{b}}$ \\
\hline 8 & Gallocatechin & $5887 \pm 273^{\mathrm{a}}$ & $2419 \pm 19^{\mathrm{b}}$ & $2301 \pm 43^{\mathrm{b}, \mathrm{c}}$ & $1960 \pm 77^{c}$ \\
\hline 9 & Prodelphinidin dimer isomer & $5452 \pm 308^{\mathrm{a}}$ & $1526 \pm 4^{\mathrm{b}}$ & $1688 \pm 40^{\mathrm{b}}$ & $1309 \pm 34^{\mathrm{b}}$ \\
\hline 10 & Geraniin isomer & $1396 \pm 47^{\mathrm{a}}$ & $304 \pm 1^{\mathrm{b}}$ & $318 \pm 12^{\mathrm{b}}$ & $201 \pm 8^{\mathrm{c}}$ \\
\hline 11 & Pedunculagin/casuariin isomer & $2894 \pm 46^{\mathrm{a}}$ & $687 \pm 9^{c}$ & $814 \pm 19^{\mathrm{b}}$ & $624 \pm 6^{c}$ \\
\hline 12 & Geraniin isomer & $2333 \pm 160^{\mathrm{a}}$ & $433 \pm 26^{\mathrm{b}}$ & $457 \pm 8^{\mathrm{b}}$ & $304 \pm 3^{\mathrm{b}}$ \\
\hline 13 & Procyanidin B isomer & $17659 \pm 785^{\mathrm{a}}$ & $6703 \pm 124^{\mathrm{b}}$ & $7106 \pm 51^{\mathrm{b}}$ & $6105 \pm 34^{\mathrm{b}}$ \\
\hline 14 & Procyanidin B isomer & $1751 \pm 150^{\mathrm{a}}$ & $398 \pm 10^{\mathrm{b}}$ & $413 \pm 10^{\mathrm{b}}$ & $321 \pm 9^{b}$ \\
\hline 15 & Tellimagrandin I isomer & $728 \pm 26^{\mathrm{a}}$ & $141 \pm 2^{c}$ & $184 \pm 5^{\mathrm{b}}$ & $129 \pm 2^{c}$ \\
\hline 16 & Catechin & $12875 \pm 705^{\mathrm{a}}$ & $6127 \pm 80^{\mathrm{b}}$ & $5960 \pm 19^{\mathrm{b}}$ & $5192 \pm 2^{\mathrm{b}}$ \\
\hline 17 & Casuarinin/casuarictin isomer & $8725 \pm 216^{\mathrm{a}}$ & $482 \pm 1^{c}$ & $859 \pm 21^{b}$ & $590 \pm 17^{\mathrm{b}, \mathrm{c}}$ \\
\hline 18 & Tellimagrandin I isomer & $1492 \pm 46^{\mathrm{a}}$ & $186 \pm 6^{\mathrm{b}, \mathrm{c}}$ & $243 \pm 9^{b}$ & $164 \pm 3^{c}$ \\
\hline 19 & Gallocatechin & $5866 \pm 362^{\mathrm{a}}$ & $2205 \pm 134^{\mathrm{b}, \mathrm{c}}$ & $2446 \pm 21^{\mathrm{b}}$ & $1896 \pm 13^{\mathrm{c}}$ \\
\hline 20 & Myricetin-arabinoside/xylopyranoside isomer & $608 \pm 18^{\mathrm{a}}$ & $<\mathrm{LOQ}$ & $<$ LOQ & $<$ LOQ \\
\hline 21 & Procyanidin B isomer 2 & $1206 \pm 56^{\mathrm{a}}$ & $207 \pm 14^{\mathrm{b}, \mathrm{c}}$ & $224 \pm 7^{b}$ & $136 \pm 6^{c}$ \\
\hline 22 & Myricetin hexoside isomer & $1301 \pm 44^{\mathrm{a}}$ & $<$ LOQ & $<$ LOQ & $<$ LOQ \\
\hline 23 & Myricetin hexoside isomer & $331 \pm 2^{\mathrm{a}}$ & $245 \pm 2^{c}$ & $299 \pm 3^{b}$ & $232 \pm 4^{\mathrm{d}}$ \\
\hline 24 & Myricetin-arabinoside/xylopyranoside isomer & $639 \pm 29^{\mathrm{a}}$ & $<$ LOQ & $<$ LOQ & $<$ LOQ \\
\hline 25 & Quercetin-galloylhexoside isomer & $566 \pm 20^{\mathrm{a}}$ & $148.3 \pm 0.1^{\mathrm{b}}$ & $171 \pm 2^{b}$ & $149 \pm 1^{b}$ \\
\hline 26 & Quercetin-galloylhexoside isomer & $452 \pm 15^{\mathrm{a}}$ & $97.25 \pm 0.02^{\mathrm{b}}$ & $102.3 \pm 0.4^{\mathrm{b}}$ & $92.25 \pm 0.07^{\mathrm{b}}$ \\
\hline 27 & Myricetin-arabinoside/xylopyranoside isomer & $592 \pm 24^{\mathrm{a}}$ & $<$ LOQ & $<$ LOQ & $<$ LOQ \\
\hline 28 & Morin & $8377 \pm 464^{\mathrm{a}}$ & $3235 \pm 53^{\mathrm{b}, \mathrm{c}}$ & $3676 \pm 12^{\mathrm{b}}$ & $3003 \pm 18^{c}$ \\
\hline 29 & Myricetin-arabinoside/xylopyranoside isomer & $986 \pm 28^{\mathrm{a}}$ & $<$ LOQ & $<$ LOQ & $<$ LOQ \\
\hline 30 & Ellagic acid & $4338 \pm 234^{\mathrm{a}}$ & $1082 \pm 16^{\mathrm{b}}$ & $1367 \pm 14^{\mathrm{b}}$ & $1040 \pm 9^{b}$ \\
\hline 31 & Hyperin & $7798 \pm 280^{\mathrm{a}}$ & $2492 \pm 6^{\mathrm{c}}$ & $2891 \pm 7^{\mathrm{b}}$ & $2031 \pm 18^{\mathrm{d}}$ \\
\hline 32 & Quercetin glucuronide & $2293 \pm 91^{\mathrm{a}}$ & $1249 \pm 19^{c}$ & $1612 \pm 40^{\mathrm{b}}$ & $1132 \pm 7^{\mathrm{c}}$ \\
\hline 33 & Isoquercitrin & $4408 \pm 182^{\mathrm{a}}$ & $1111 \pm 19^{\mathrm{b}, \mathrm{c}}$ & $1306 \pm 5^{\mathrm{b}}$ & $996 \pm 3^{c}$ \\
\hline 34 & Reynoutrin & $5849 \pm 173^{\mathrm{a}}$ & $1386 \pm 21^{\mathrm{b}, \mathrm{c}}$ & $1611 \pm 20^{\mathrm{b}}$ & $1229 \pm 9^{c}$ \\
\hline 35 & Guajaverin & $12843 \pm 421^{\mathrm{a}}$ & $3169 \pm 40^{\mathrm{b}, \mathrm{c}}$ & $3595 \pm 4^{\mathrm{b}}$ & $2713 \pm 36^{c}$ \\
\hline 36 & Guavinoside A & $1920 \pm 40^{\mathrm{a}}$ & $453 \pm 3^{c}$ & $522 \pm 1^{\mathrm{b}}$ & $413 \pm 2^{\mathrm{c}}$ \\
\hline 37 & Avicularin & $13666 \pm 421^{\mathrm{a}}$ & $3825 \pm 48^{\mathrm{b}}$ & $4183 \pm 34^{\mathrm{b}}$ & $3232 \pm 25^{\mathrm{c}}$ \\
\hline 38 & Quercitrin & $6822 \pm 274^{\mathrm{a}}$ & $1825 \pm 39^{\mathrm{b}}$ & $2078 \pm 24^{\mathrm{b}}$ & $1705 \pm 12^{\mathrm{b}}$ \\
\hline 39 & Guavinoside C & $2298 \pm 40^{\mathrm{a}}$ & $<$ LOQ & $<$ LOQ & $<$ LOQ \\
\hline 40 & Guavinoside B & $1456 \pm 34^{\mathrm{a}}$ & $370 \pm 3^{c}$ & $423 \pm 4^{\mathrm{b}}$ & $328.6 \pm 0.1^{\mathrm{c}}$ \\
\hline 41 & Guavinoside A isomer & $558 \pm 4^{\mathrm{a}}$ & $177 \pm 1^{b}$ & $160 \pm 4^{\mathrm{c}}$ & $140.0 \pm 0.3^{\mathrm{d}}$ \\
\hline 42 & Prodelphinidin B2 isomer 2 & $<$ LOQ & $<$ LOQ & $<$ LOQ & $<$ LOQ \\
\hline 43 & Guavinoside B isomer & $<$ LOQ & $<$ LOQ & $<$ LOQ & $<$ LOQ \\
\hline 44 & Guavinoside B isomer & $<\mathrm{LOQ}$ & nd & nd & nd \\
\hline 45 & Guavinoside B isomer & $<$ LOQ & nd & nd & nd \\
\hline 46 & Guavin B & $460 \pm 6^{\mathrm{a}}$ & $34 \pm 1^{b}$ & $32.2 \pm 0.2^{\mathrm{b}}$ & $20 \pm 1^{\mathrm{c}}$ \\
\hline 47 & Quercetin & $408 \pm 18^{\mathrm{a}}$ & nd & nd & nd \\
\hline 48 & Naringenin & $538 \pm 14^{\mathrm{c}}$ & $941 \pm 3^{\mathrm{a}}$ & $815 \pm 24^{\mathrm{b}}$ & $558 \pm 9^{c}$ \\
\hline
\end{tabular}

n.d.: not detected; AE: aqueous extract obtained by ultrasound; I3, I5, and I7: infusion obtained at 3, 5, and 7 minutes of infusion time, respectively. The different letter in the same line means that the compounds are significantly different $(P \leq 0.05)$. 


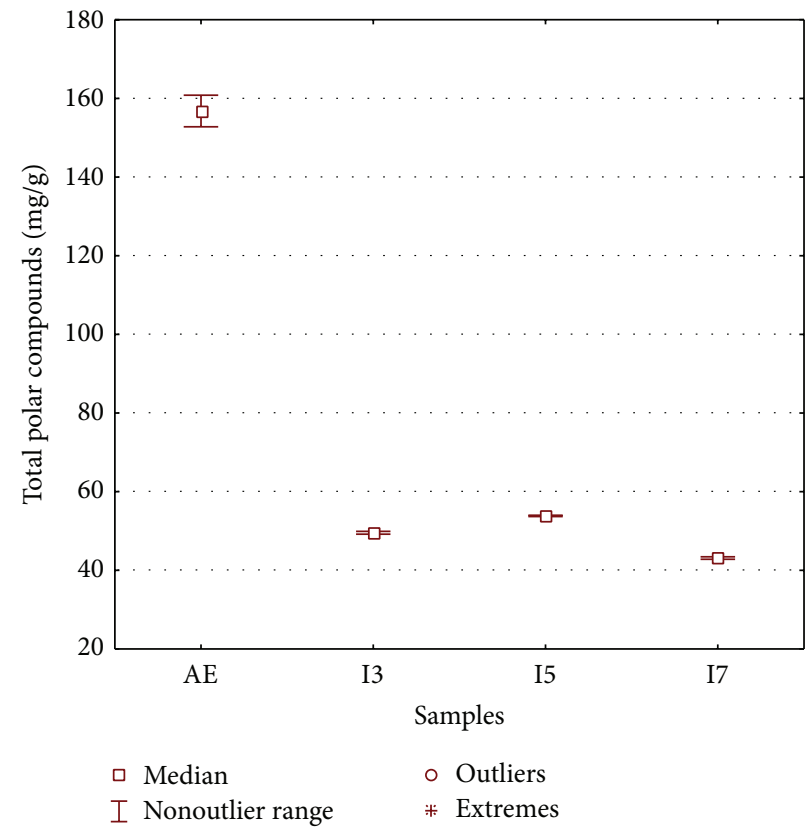

FIGURE 1: Total content (mg/g) of total polar compounds by HPLC in analysed samples.

TABLE 3: Comparison between total polar compound $(\mathrm{mg} / \mathrm{g})$ determined by HPLC and antioxidant activity evaluated by $\mathrm{FRAP}(\mu \mathrm{M}$ of FeSO equivalents/mg) and ABTS ( $\mu \mathrm{M}$ of Trolox equivalents/mg).

\begin{tabular}{lccc}
\hline Sample & TPC by HPLC & FRAP & ABTS \\
\hline AE & $157 \pm 6.0^{\mathrm{a}}$ & $3026.7 \pm 586.4^{\mathrm{a}}$ & $1127.6 \pm 69.0^{\mathrm{a}}$ \\
I3 & $49.6 \pm 0.5^{\mathrm{c}}$ & $314.2 \pm 15.1^{\mathrm{b}}$ & $155.7 \pm 1.1^{\mathrm{b}}$ \\
I5 & $53.8 \pm 0.2^{\mathrm{b}}$ & $285.3 \pm 7.0^{\mathrm{b}}$ & $217.6 \pm 19.2^{\mathrm{b}}$ \\
I7 & $43.1 \pm 0.4^{\mathrm{d}}$ & $285.7 \pm 7.0^{\mathrm{b}}$ & $178.2 \pm 1.3^{\mathrm{b}}$ \\
\hline
\end{tabular}

Means in the same column with different letter are significantly different $(P<0.05)$.

(Table 3). Besides, the reducing power and radical scavenging capacity displayed a significative difference between the samples obtained by infusion and the ultrasound aqueous extract. Positive correlations with $R=0.9883$ and $P<0.001$ and $R=0.9973$ and $P<0.001$ were noticed between total polar compounds content and FRAP and ABTS, respectively.

FRAP and ABTS did not report significative differences $(P<0.05)$ among infusion samples; however, ultrasound aqueous extract values were higher than infusions values.

Moreover, a simple linear regression analysis was carried out to compare the correlation between all compounds identified and the antioxidant activity (Table 4).

Most of the polar compounds were highly correlated with FRAP assay $(R=0.98 ; P<0.001)$ except compounds 10,30 , and 32 that reported an $R$ value ranging between 0.96 and 0.97 $(P<0.001)$. Compound 23 showed a lower correlation $(R=$ 0.76; $P<0.05)$. HHDP glucose isomers resulted in inverse correlation with FRAP assay. Moreover, naringenin did not show any correlation.

ABTS assay confirmed data reported by FRAP assay; in fact, the two antioxidant assays showed a good correlation between them that reported an $R$ value of 0.9916 and $P<$ 0.0001 . These results agreed with the data reported by Thaipong et al. [24].

\section{Conclusions}

Several polar compounds have been identified and quantified in guava leaves extracts (ultrasound aqueous extract and infusions). According to the amount of polar compounds and also the FRAP and ABTS assays, the water ultrasound assisted extraction provided better results than the infusion. Significative positive correlations $R>0.98$ and $P<0.001$ were detected between total polar content and antioxidant activity assays. Moreover, positive correlation was also detected for single compounds, except for HHDP and naringenin.

The results suggested that aqueous ultrasound extract can represent a valuable strategy to obtain nutraceuticals using a green technology. About infusions, the 5-minute infusion is advisable for guava leaves culinary uses because of reported higher polar compounds content. 
TABLE 4: Correlation between the antioxidant activity and polar compounds.

\begin{tabular}{|c|c|c|c|c|c|}
\hline \multicolumn{2}{|r|}{ Compounds } & \multicolumn{2}{|c|}{ FRAP } & \multicolumn{2}{|c|}{ ABTS } \\
\hline & & $R$ value & $P$ value & $R$ value & $P$ value \\
\hline 1 & HHDP glucose isomer & -0.9644 & $* * *$ & -0.9721 & $* * *$ \\
\hline 2 & HHDP glucose isomer & -0.8199 & * & -0.8321 & * \\
\hline 3 & HHDP glucose isomer & -0.7507 & * & -0.7700 & * \\
\hline 4 & Gallic acid & 0.992 & $* * *$ & 0.9993 & $* * *$ \\
\hline 5 & Prodelphinidin B2 isomer & 0.9817 & $* * *$ & 0.9845 & $* * *$ \\
\hline 6 & Pedunculagin/casuariin isomer & 0.9849 & $* * *$ & 0.9980 & $* * *$ \\
\hline 7 & Prodelphinidin dimer isomer & 0.9895 & $* * *$ & 0.9962 & $* * *$ \\
\hline 8 & Gallocatechin & 0.9887 & $* * *$ & 0.9922 & $* * *$ \\
\hline 9 & Prodelphinidin dimer isomer & 0.9909 & $* * *$ & 0.9977 & $* * *$ \\
\hline 10 & Geraniin isomer & 0.9747 & $* * *$ & 0.9911 & $* * *$ \\
\hline 11 & Pedunculagin/casuariin isomer & 0.985 & $* * *$ & 0.9979 & $* * *$ \\
\hline 12 & Geraniin isomer & 0.9922 & $* * *$ & 0.9911 & $* * *$ \\
\hline 13 & Procyanidin B isomer & 0.9907 & $* * *$ & 0.9978 & $* * *$ \\
\hline 14 & Procyanidin B isomer & 0.9949 & $* * *$ & 0.9973 & $* * *$ \\
\hline 15 & Tellimagrandin I isomer & 0.987 & $* * *$ & 0.9985 & $* * *$ \\
\hline 16 & Catechin & 0.99 & $* * *$ & 0.9916 & $* * *$ \\
\hline 17 & Casuarinin/casuarictin isomer & 0.9874 & $* * *$ & 0.9990 & $* * *$ \\
\hline 18 & Tellimagrandin I isomer & 0.9881 & $* * *$ & 0.9989 & $* * *$ \\
\hline 19 & Gallocatechin & 0.9881 & $* * *$ & 0.994 & $* * *$ \\
\hline 20 & Myricetin-arabinoside/xylopyranoside isomer & 0.9889 & $* * *$ & 0.9978 & $* * *$ \\
\hline 21 & Procyanidin B isomer 2 & 0.9891 & $* * *$ & 0.9967 & $* * *$ \\
\hline 22 & Myricetin hexoside isomer & 0.9893 & $* * *$ & 0.9979 & $* * *$ \\
\hline 23 & Myricetin hexoside isomer & 0.7694 & * & 0.8073 & * \\
\hline 24 & Myricetin-arabinoside/xylopyranoside isomer & 0.9907 & $* * *$ & 0.9981 & $* * *$ \\
\hline 25 & Quercetin-galloylhexoside isomer & 0.9893 & $* * *$ & 0.9994 & $* * *$ \\
\hline 26 & Quercetin-galloylhexoside isomer & 0.99 & $* * *$ & 0.9986 & $* * *$ \\
\hline 27 & Myricetin-arabinoside/xylopyranoside isomer & 0.9901 & $* * *$ & 0.9980 & $* * *$ \\
\hline 28 & Morin & 0.9889 & $* * *$ & 0.9967 & $* * *$ \\
\hline 29 & Myricetin-arabinoside/xylopyranoside isomer & 0.9887 & $* * *$ & 0.9977 & $* * *$ \\
\hline 30 & Ellagic acid & 0.9684 & $* * *$ & 0.9915 & $* * *$ \\
\hline 31 & Hyperin & 0.983 & $* * *$ & 0.9938 & $* * *$ \\
\hline 32 & Quercetin glucuronide & 0.9622 & $* * *$ & 0.9794 & $* * *$ \\
\hline 33 & Isoquercitrin & 0.9887 & $* * *$ & 0.9983 & $* * *$ \\
\hline 34 & Reynoutrin & 0.9874 & $* * *$ & 0.9982 & $* * *$ \\
\hline 35 & Guajaverin & 0.9878 & $* * *$ & 0.9978 & $* * *$ \\
\hline 36 & Guavinoside A & 0.9866 & $* * *$ & 0.9982 & $* * *$ \\
\hline 37 & Avicularin & 0.9874 & $* * *$ & 0.9970 & $* * *$ \\
\hline 38 & Quercitrin & 0.9897 & $* * *$ & 0.9989 & $* * *$ \\
\hline 39 & Guavinoside C & 0.9873 & $* * *$ & 0.9974 & $* * *$ \\
\hline 40 & Guavinoside B & 0.9864 & $* * *$ & 0.9979 & $* * *$ \\
\hline 41 & Guavinoside A isomer & 0.9842 & $* * *$ & 0.9928 & $* * *$ \\
\hline 46 & Guavin B & 0.9865 & $* * *$ & 0.9968 & $* * *$ \\
\hline 47 & Quercetin & 0.9906 & $* * *$ & 0.9981 & $* * *$ \\
\hline 48 & Naringenin & -0.5619 & $\mathrm{NC}$ & -0.5855 & $\mathrm{NC}$ \\
\hline & TPC by HPLC & 0.9883 & $* * *$ & 0.9973 & $* * *$ \\
\hline
\end{tabular}

${ }^{* * *} P<0.001 ;{ }^{*} P<0.05$; NC: not correlated. 


\section{Conflict of Interests}

The authors declare that there is no conflict of interests regarding the publication of this paper.

\section{Acknowledgments}

This work was funded by the Project cofinanced by FEDERAndalucía 2007-2013 (Cod. 461100) and Andalusian Regional Government Council of Innovation and Science (P11-CTS7625). The author Elixabet Díaz-de-Cerio also would like to thank the CEIBiotic for the "Ayudas a la Enseñanza Práctica” Grant (CADP2-71). Ana María Gómez-Caravaca and Vito Verardo thank the Spanish Ministry of Economy and Competitiveness (MINECO) for "Juan de la Cierva" postdoctoral contract.

\section{References}

[1] Q.-M. Liu and J.-G. Jiang, "Antioxidative activities of medicinal plants from TCM," Mini-Reviews in Medicinal Chemistry, vol. 12, no. 11, pp. 1154-1172, 2012.

[2] S. Z. Bathaie, N. Mokarizade, and S. Shirali, "An overview of the mechanisms of plant ingredients in the treatment of diabetes mellitus," Journal of Medicinal Plants, vol. 11, no. 44, pp. 1-24, 2012.

[3] U. Etxeberria, A. L. de la Garza, J. Campin, J. A. Martnez, and F. I. Milagro, "Antidiabetic effects of natural plant extracts via inhibition of carbohydrate hydrolysis enzymes with emphasis on pancreatic alpha amylase," Expert Opinion on Therapeutic Targets, vol. 16, no. 3, pp. 269-297, 2012.

[4] R. M. P. Gutiérrez, S. Mitchell, and R. V. Solis, "Psidium guajava: a review of its traditional uses, phytochemistry and pharmacology," Journal of Ethnopharmacology, vol. 117, no. 1, pp. $1-27,2008$.

[5] J. T. Cheng and R. S. Yang, "Hypoglycemic effect of guava juice in mice and human subjects," The American Journal of Chinese Medicine, vol. 11, no. 1-4, pp. 74-76, 1983.

[6] T. Eidenberger, M. Selg, and K. Krennhuber, "Inhibition of dipeptidyl peptidase activity by flavonol glycosides of guava (Psidium guajava L.): a key to the beneficial effects of guava in type II diabetes mellitus," Fitoterapia, vol. 89, no. 1, pp. 74-79, 2013.

[7] F.-C. Cheng, S.-C. Shen, and J. S.-B. Wu, "Effect of guava (Psidium guajava L.) leaf extract on glucose uptake in rat hepatocytes," Journal of Food Science, vol. 74, no. 5, pp. H132H138, 2009.

[8] H.-Y. Chen and G.-C. Yen, "Antioxidant activity and free radical-scavenging capacity of extracts from guava (Psidium guajava L.) leaves," Food Chemistry, vol. 101, no. 2, pp. 686-694, 2007.

[9] O. Laporta, L. Pérez-Fons, R. Mallavia, N. Caturla, and V. Micol, "Isolation, characterization and antioxidant capacity assessment of the bioactive compounds derived from Hypoxis rooperi corm extract (African potato)," Food Chemistry, vol. 101, no. 4, pp. 1425-1437, 2007.

[10] I. F. F. Benzie and J. J. Strain, "The ferric reducing ability of plasma (FRAP) as a measure of 'antioxidant power': the FRAP assay," Analytical Biochemistry, vol. 239, no. 1, pp. 70-76, 1996.

[11] C. H. Chang, C. L. Hsieh, H. E. Wang, C. C. Peng, C. C. Chyau, and R. Y. Peng, "Unique bioactive polyphenolic profile of guava (Psidium guajava) budding leaf tea is related to plant biochemistry of budding leaves in early dawn," Journal of the Science of Food and Agriculture, vol. 93, no. 4, pp. 944-954, 2013.

[12] T. Okuda, T. Yoshida, T. Hatano, K. Yazaki, and M. Ashida, "Ellagitannins of the casuarinaceae, stachyuraceae and myrtaceae," Phytochemistry, vol. 21, no. 12, pp. 2871-2874, 1980.

[13] F. A. Yamanaka, T. A. Hatano, H. A. Ito, S. B. Taniguchi, E. C. Takahashi, and K. C. Okamoto, "Antibacterial effects of guava tannins and related polyphenols on Vibrio and Aeromonas species," Natural Product Communications, vol. 3, no. 5, pp. 711720, 2008.

[14] T. Okuda, T. Hatano, and K. Yazaki, "Guavin B, an ellagitannin of novel type," Chemical \& Pharmaceutical Bulletin, vol. 32, no. 9, pp. 3787-3788, 1984.

[15] F. Qa'Dan, F. Petereit, and A. Nahrstedt, "Polymeric proanthocyanidins from Psidium guajava," Scientia Pharmaceutica, vol. 73, no. 3, pp. 113-125, 2005.

[16] B.-J. Park, T. Matsuta, T. Kanazawa, C.-H. Park, K.-J. Chang, and M. Onjo, "Phenolic compounds from the leaves of Psidium guajava II. quercetin and its glycosides," Chemistry of Natural Compounds, vol. 48, no. 3, pp. 477-479, 2012.

[17] S. Tachakittirungrod, F. Ikegami, and S. Okonogi, "Antioxidant active principles isolated from Psidium guajava grown in Thailand," Scientia Pharmaceutica, vol. 75, no. 4, pp. 179-193, 2007.

[18] K.-C. Chen, C.-M. Chuang, L.-Y. Lin et al., "The polyphenolics in the aqueous extract of Psidium guajava kinetically reveal an inhibition model on LDL glycation," Pharmaceutical Biology, vol. 48, no. 1, pp. 23-31, 2010.

[19] K. Matsuzaki, R. Ishii, K. Kobiyama, and S. Kitanaka, "New benzophenone and quercetin galloyl glycosides from Psidium guajava L.," Journal of Natural Medicines, vol. 64, no. 3, pp. 252256, 2010.

[20] W. Nantitanon, S. Yotsawimonwat, and S. Okonogi, "Factors influencing antioxidant activities and total phenolic content of guava leaf extract," LWT-Food Science and Technology, vol. 43, no. 7, pp. 1095-1103, 2010.

[21] P. Zhang, R. Lin, G. Yang, J. Zhang, L. Zhou, and T. Liu, "Solubility of naringenin in ethanol and water mixtures," Journal of Chemical and Engineering Data, vol. 58, no. 9, pp. 2402-2404, 2013.

[22] J. Wen, B. Liu, E. Yuan, Y. Ma, and Y. Zhu, "Preparation and physicochemical properties of the complex of naringenin with hydroxypropyl- $\beta$-cyclodextrin," Molecules, vol. 15 , no. 6, pp. 4401-4407, 2010.

[23] H. Wang, Y.-J. Du, and H.-C. Song, " $\alpha$-Glucosidase and $\alpha$ amylase inhibitory activities of guava leaves," Food Chemistry, vol. 123, no. 1, pp. 6-13, 2010.

[24] K. Thaipong, U. Boonprakob, K. Crosby, L. Cisneros-Zevallos, and D. H. Byrne, "Comparison of ABTS, DPPH, FRAP, and ORAC assays for estimating antioxidant activity from guava fruit extracts," Journal of Food Composition and Analysis, vol. 19, no. 6-7, pp. 669-675, 2006. 

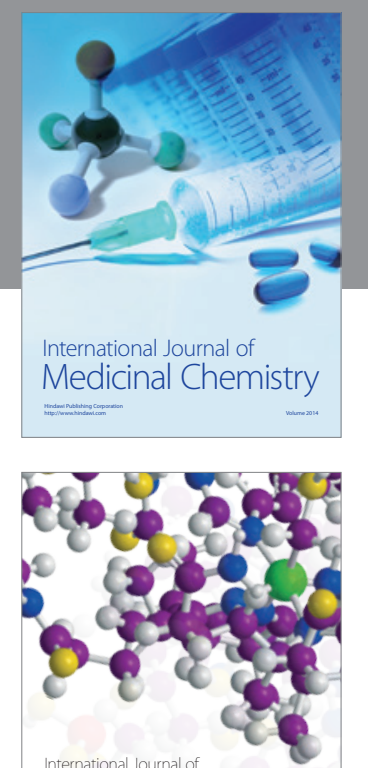

\section{Carbohydrate} Chemistry

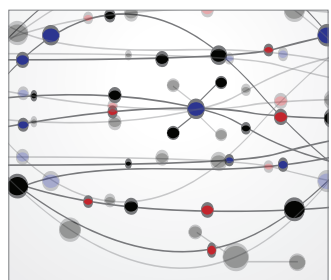

The Scientific World Journal
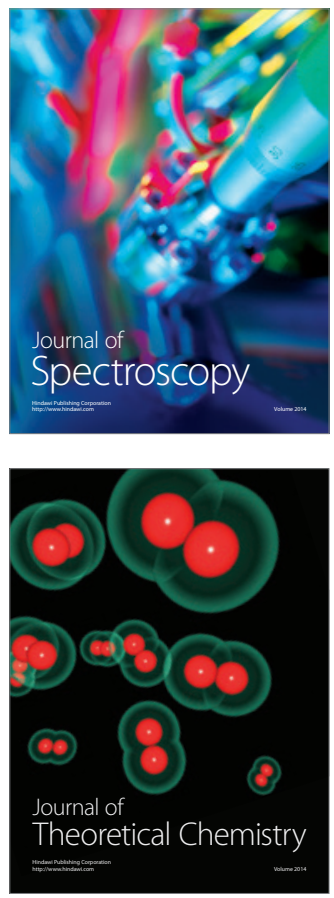
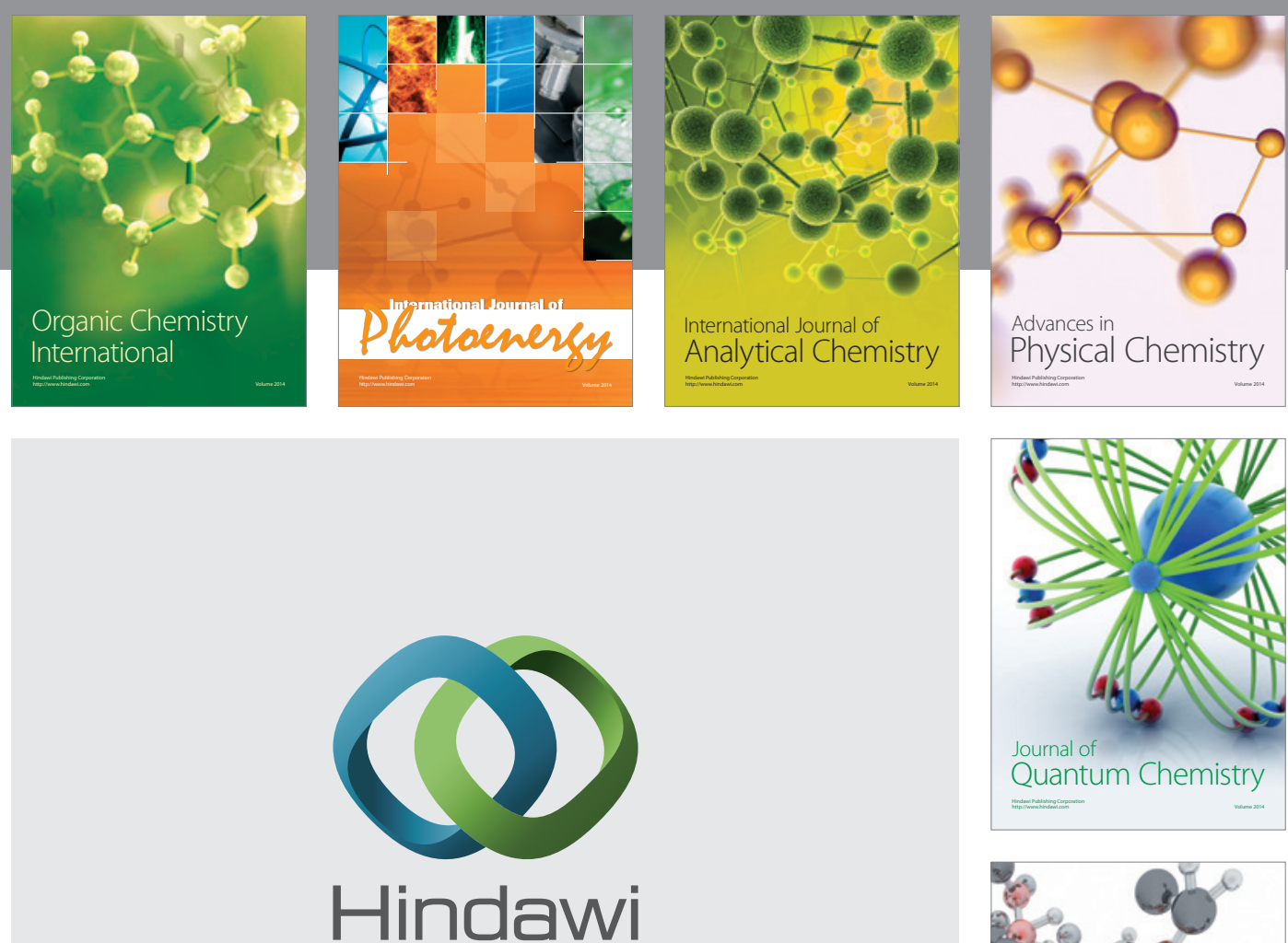

Submit your manuscripts at

http://www.hindawi.com

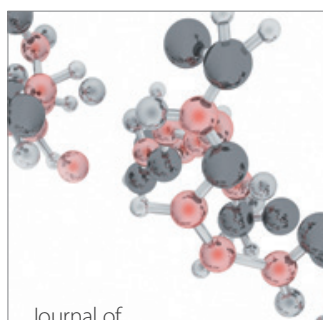

Analytical Methods

in Chemistry

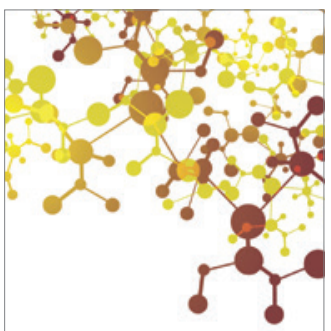

Journal of

Applied Chemistry

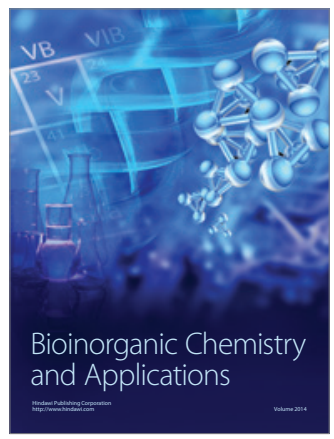

Inorganic Chemistry
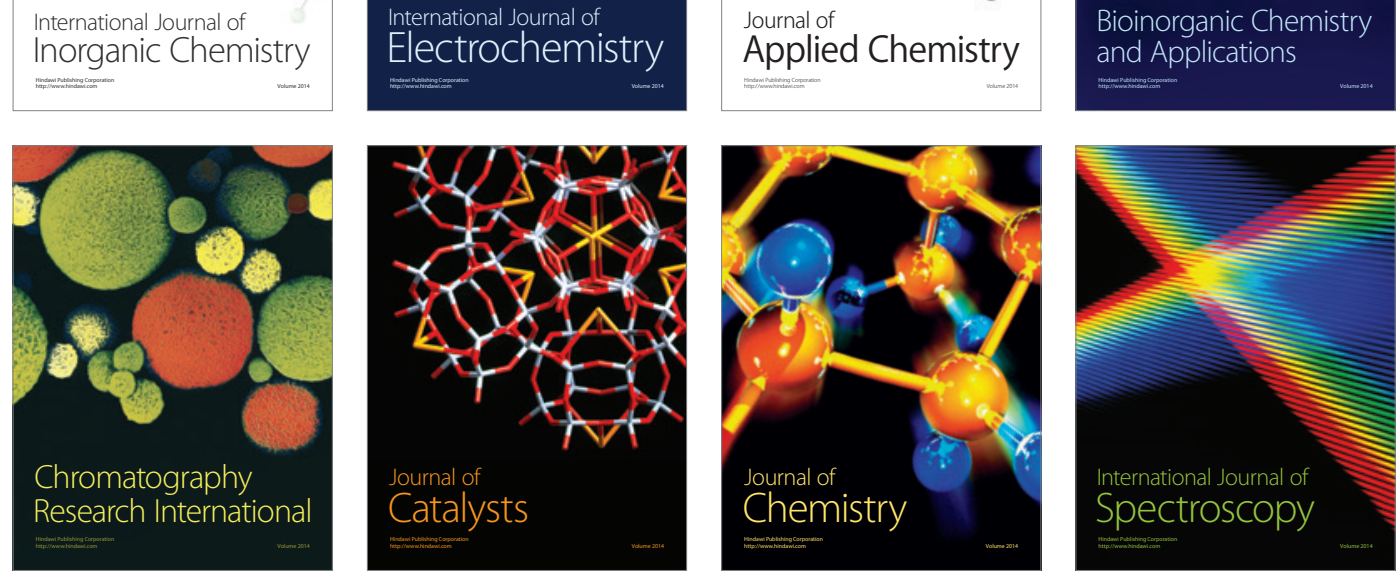